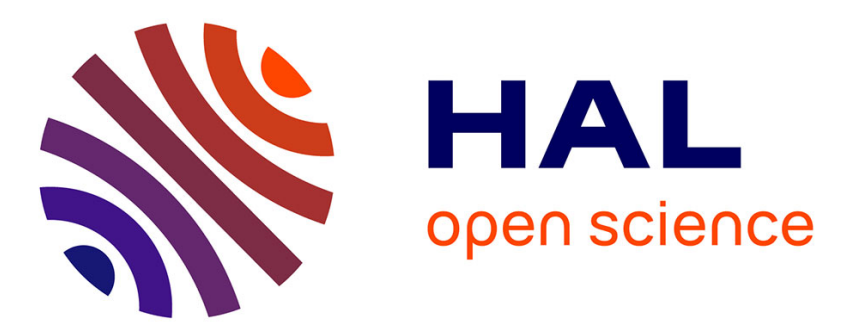

\title{
Positron annihilation lifetime (PAL) estimation of backscatter coefficients: ingredients for data correction
}

\author{
A. Saoucha
}

\section{To cite this version:}

A. Saoucha. Positron annihilation lifetime (PAL) estimation of backscatter coefficients: ingredients for data correction. Journal de Physique IV Proceedings, 1993, 03 (C4), pp.C4-77-C4-81. 10.1051/jp4:1993408 . jpa-00251451

\section{HAL Id: jpa-00251451 https://hal.science/jpa-00251451}

Submitted on 1 Jan 1993

HAL is a multi-disciplinary open access archive for the deposit and dissemination of scientific research documents, whether they are published or not. The documents may come from teaching and research institutions in France or abroad, or from public or private research centers.
L'archive ouverte pluridisciplinaire HAL, est destinée au dépôt et à la diffusion de documents scientifiques de niveau recherche, publiés ou non, émanant des établissements d'enseignement et de recherche français ou étrangers, des laboratoires publics ou privés. 


\title{
Positron annihilation lifetime (PAL) estimation of backscatter coefficients: ingredients for data correction
}

\section{A. SAOUCHA}

Centre de Développement des Techniques Nucléaires, 2 Bd. Frantz Fanon, BP. 1017, Alger-Gare, Algeria

\begin{abstract}
Backscatter coefficients for a small variety of metals have been measured by PAL technique. "Source-surface" percentage contributions are presented for various specimens.
\end{abstract}

\section{1.. - INTRODUCTION}

For a point, isotropic, heteroenergetic, single $\beta^{+}$decay mode source, the fraction of positrons annihilating outside the bulk matrix of a typical sample sandwich configuration (Fig. 1) is, ignoring backscattering for the moment, presented as (1):

$$
P(\alpha z)=1-\exp (-\alpha z)-\alpha z \operatorname{Ei}(-\alpha z)
$$

where $E_{i}$ is the exponential integral function, $\alpha$ is the absorption coefficient of the source-confining material, and $z$ is the corresponding thickness.

PAL spectra involve contributing effects from source, foil and surfaces (2). Moreover, because of the backscattering process, reflected positrons may cross the source (imaginary) plane several times, contributing hence a non-negligeable probability of absorption outside the homogeneous interior of the lattice under study (3). Therefore, az should be replaced by $a_{t} z$ ( $t$ for total) and [1] should be presented as the sum of contributions from all possible trajectories.

2. - MODEL

Replacing $\alpha z$ by $\alpha_{t} z_{t}$. neglecting backscattering from the foil, assuming no energy dependence for the backscatter coefficient $R$, and postulating that incident (on one side of the presumed symmetrical sandwich arrangement) and reflected (off that same side) positrons get implanted with the same profile, the complete functional form of [1] is then obtained by summing all contributions from the infinite series of reflections sketched in Fig 1 . This yields:

$$
Q=P+R(1-P) P^{\prime} /\left[1-R\left(1-P^{\prime}\right)\right]
$$

where $P=P\left(\alpha_{t} z_{t}\right)$ and $P^{\prime}=P\left(2 \alpha_{t} z_{t}\right)$, so that:

$$
R=(Q-P) /\left(P^{\prime}-P+Q-P^{\prime} Q\right)
$$


Integration over $2 \pi$ solid angle (1.3) means even positrons emitted laterally with respect to the main axis are taken into account in the multiple backscattering process. Such a picture which may not reflect reality is likely to result in a little overestimation of the quantity under consideration. Now, supressing the last (correction) term in [1], [3] becomes (for small $\alpha_{k} z_{k}$ ):

$$
R=(Q-P) /(Q+P-2 P Q)
$$

i.e. an expression for multiple backscattering along the direction of collimated positrons from sodium-22. Therefore, the true $R$ is expected to be within the limits set by [3] and [4].

3. - RESULTS

The experimental set-up and the analysis procedure were as described in Ref 2. The "source-surface" lifetimes, seen in Fig. 2 . distributed around the mean value $433 \mathrm{ps}$ with no systematic trend.

$R$ being $Z$-dependent ( 3 ), the percentage-contributions, If and Is, for absorption in the foil $(0.5 \mu \mathrm{m} \mathrm{Ni})$ and for annihilation in the "source-surface" sites, for each metal. were determined using (copper) the reference sample and scaling If/Is to the ratio of the latter. This procedure was iterated until reaching steady values for If and Is. Determination of $R$ from [3] or [4] requires estimating $P$. i.e. $\alpha_{t} z_{t}$ and $P^{\prime}$. from data of a low-Z material. e.g. beryllium $(Z=4)$. But owing to the strict safety measures accompagning use of the latter, kapton $(Z=4.2)$ was chosen instead. In common with annealed metals, kapton displays a single lifetime component of some $380 \mathrm{ps}$. However, it may not involve surface-effects like these. So the idea was to measure the fraction of positrons annihilating in the foil with kapton as surrounding material and to deduce from the scaling above what would be roughly Is for beryllium if one were to use the latter instead of kapton. Performing this, a value $P=0.046$ \pm 0.005 was obtained. Resulting values of $R$ from [3] and [4] are shown in Table 1. The uncertainty is typically 0.09 . Comparison is made with results of Mackenzie et al. (3) from measurement geometry similar to that in here, and also with results of Arifovet al. (4) obtained for collimated positrons emitted by sodium-22. Agreement is reached within the uncertainty of the present measurements. validating therefore equation [2] for correcting experimental data.

To improve the measurements and to avoid doing a model-dependent determination of $R$, a series of experiments with configuration "metal-source-polystyrene", were carried out assuming no positron reflection from the polymeric part of this mixed sample arrangement. The spectrum characteristic of polystyrene, i.e. the reference one, was resolved in terms of three components for parapositronium decay, free annihilation, and pick-off annihilation of positrons bound in orthopositronium. The third component with lifetime 2 ns gave intensity $\mathrm{Ia}=40.25 \pm 0.08$. The desired backscatter coefficient $R^{\prime}$ was then extracted. from the relative increase in the intensity Ia associated with the longlived. well-separated component due to pick-off annihilation in the polymeric counterpart of the selected metal. Results for $R$ ' are shown in table 1. The uncertainty is typically 0.004 .

In most $P A L$ investigations, people deal with defected specimens. Therefore, the influence of defects on $I_{s}$ must be evaluated if one is to ensure proper correction to the experimental data. One expects the mean length of positrons diffusing to the surface of a layer to depend on the defect-state of the latter (2). 
Table 2 contains values of Is for various specimens. The observed behaviour of Is seems compatible with what has been already pointed out to in Ref.2. Is increases by some $0.5 \%$ for each added foil. More contribution is seen with the reduced density of dislocations in the "as-annealed" $2.5 \mathrm{~mm}$ additional $\mathrm{Ni}$ foil. Defected samples lead to some 1 \% discrepancy in Is with respect to anneal-cases.

\section{4. - CONCLUSION}

Extraction of coefficients for backscatter into $2 \pi$ solid angle from "source-contributions" and comparison "with commonly accepted relations $(3,4)$ were just intended to validate equations $53 J^{2}$ and [4] for correcting experimental data.

As expected, the model-independent determination of $R$ gave results falling between values from $R e f .3$ and Ref.4, although most of these results are rather close to those of the former reference. The influence of defects and/or of additional foils on the "source-surface" component is made evident.

"Source-surface" contributions determined for annealed samples have to be modified (by some $1 \%$ ) before being used to correct the results for defected samples.

\section{ACKNOWLEDGEMENT}

I wish to thank M. Eldrup and N.J. Pedersen for help, support and discussions.

\section{REFERENCES}

1) Schrader, D.M., Chiu, S.W., Nakanishi, H., and Rochanakij, S., Pos. Ann., eds. Jain, P.C., Singru, R.M., and Gopinathan, K.P.. 1985 (World Scientific) p. 822, and Schrader. D.M., in: Positron and Positronium Chemistry. Studies in Physical and Theoretical Chemistry 57, chap. 2, eds. Schrader, D.M., and Jean, Y.C., 1988 (Elsevier. Amsterdam).

2) Saoucha. A.. Pedersen, N.J., and Eldrup, M., Pos. Ann., ods. Kajcsos, Z., Szeles, C., 1991 (Trans. Tech) p. 1971.

3) Mackenzie, I.K.. Schutle, C.W., Jackman, T., and Campbell, J.L., Phys. Rev. A 7 (1973) 135.

4) Arifov. P.U., Grupper, A.R., and Alimkulov, H., Pos. Ann., eds. Coleman. P.G.. Sharma, S.C., and Diana, L.M. 1982 (North-Holland) p. 699 . 
Table 1.

Backscatter coefficients from "source-contributing-spectra" in conventional geometry "metal-source-metal", and from

"bulk data" in mixed configuration "metal-source-polystyrene".

\begin{tabular}{|c|c|c|c|c|c|c|c|c|}
\hline Element & $Q$ & $\Delta Q$ & $\mathrm{R}$ [3] & $R$ [4] & $R \quad(3)$ & $R$ (4) & Is & $R$ \\
\hline$A 1$ & 0.070 & 0.001 & 0.24 & 0.22 & 0.235 & 0.194 & 0.2420 & 0.202 \\
\hline $\mathrm{Fe}$ & 0.0807 & 0.0005 & 0.32 & 0.29 & 0.338 & 0.269 & 0.2674 & 0.328 \\
\hline $\mathrm{Cu}$ & 0.0867 & 0.0005 & 0.36 & 0.33 & 0.354 & 0.283 & 0.2689 & 0.335 \\
\hline $\mathrm{Zr}$ & 0.0917 & 0.0009 & 0.39 & 0.35 & 0.402 & 0.330 & & \\
\hline Mo & & & & & 0.409 & 0.337 & 0.2776 & 0.378 \\
\hline $\mathrm{Ag}$ & 0.106 & 0.003 & 0.46 & 0.42 & 0.426 & 0.356 & 0.2821 & 0.401 \\
\hline Pt & & & & & 0.501 & 0.452 & 0.3004 & 0.492 \\
\hline $\mathrm{Au}$ & 0.1358 & 0.0007 & 0.56 & 0.53 & 0.503 & 0.455 & & \\
\hline
\end{tabular}

Tabie 2 .

Source-surface" percentage contributions for various specimens.

\begin{tabular}{|c|c|}
\hline (Source)-(foil)-(extra foil)-(sample) configuration & Is \\
\hline$\left(\mathrm{Na}^{22}\right)-(0.5 \mu \mathrm{m} \mathrm{Ni})-($ none $)-($ annealed $\mathrm{Pt})$ & $4.8 \pm 0.1$ \\
\hline$\left(\mathrm{Na}^{22}\right)-(0.5 \mu \mathrm{m} \mathrm{Ni})-(2.5 \mu \mathrm{m}$ deformed $\mathrm{Ni})-(\mathrm{ann}$. Pt $)$ & $5.2 \pm 0.3$ \\
\hline$\left(\mathrm{Na}^{22}\right)-(0.5 \mu \mathrm{m} \mathrm{Ni})-(2.5 \mu \mathrm{m}$ def-ann. Ni)-(ann. Pt $)$ & $5.6 \pm 0.1$ \\
\hline$\left(\mathrm{Na}^{22}\right)-(0.5 \mu \mathrm{m} \mathrm{Ni})-(2.5 \mu \mathrm{m}$ def-ann-def. $\mathrm{N} i)-(\mathrm{ann} . \mathrm{Pt})$ & $5.2 \pm 0.1$ \\
\hline$\left(\mathrm{Na}^{22}\right)-(0.5 \mu \mathrm{m} \mathrm{Ni})-(2 \times 2.5 \mu \mathrm{m}$ def. $\mathrm{Ni})-(\mathrm{ann} . \mathrm{Pt})$ & $5.6 \pm 0.1$ \\
\hline$\left(\mathrm{Na}^{22}\right)-(0.5 \mu \mathrm{m} \mathrm{Ni})-($ none $)-(\mathrm{Pt}$ quenched "thermal vacancies") & $3.6 \pm 0.1$ \\
\hline$\left(\mathrm{Na}^{22}\right)-(0.5 \mu \mathrm{m} \mathrm{Ni})-($ none $)-($ annealed $\mathrm{Cu})$ & $3.8 \pm 0.1$ \\
\hline$\left(\mathrm{Na}^{22}\right)-(0.5 \mu \mathrm{m} \mathrm{Ni})-($ none $)-($ deformed $\mathrm{Cu}$ at $10 \%)$ & $3.0 \pm 0.2$ \\
\hline$\left(\mathrm{Na}^{22}\right)-(0.5 \mu \mathrm{m} \mathrm{Ni})-($ none $)-($ deformed $\mathrm{Cu}$ at $25 \%)$ & $3.1 \pm 0.2$ \\
\hline$\left(\mathrm{Na}^{22}\right)-(0.5 \mu \mathrm{m} \mathrm{Ni})-($ none $)-($ deformed $\mathrm{Cu}$ at $50 \%)$ & $2.8 \pm 0.2$ \\
\hline$\left(\mathrm{Na}^{22}\right)-(0.5 \mu \mathrm{m} \mathrm{Ni})-($ none $)-($ deformed $\mathrm{Cu}$ at $70 \%)$ & $2.7 \pm 0.2$ \\
\hline$\left(\mathrm{Na}^{22}\right)-(0.5 \mu \mathrm{m} \mathrm{Ni})-($ none $)-($ anned $\operatorname{ed~} \mathrm{Ni})$ & $3.7 \pm 0.1$ \\
\hline$\left(\mathrm{Na}^{22}\right)-(0.5 \mu \mathrm{m} \mathrm{Ni})-($ none $)-($ defected $\mathrm{Ni})$ & $3.1 \pm 0.2$ \\
\hline$\left(\mathrm{Na}^{22}\right)-(0.5 \mu \mathrm{m} \mathrm{N} i)-($ none $)-(\mathrm{Ni}$ containing krypton bubbles $)$ & $3.3 \pm 0.3$ \\
\hline
\end{tabular}




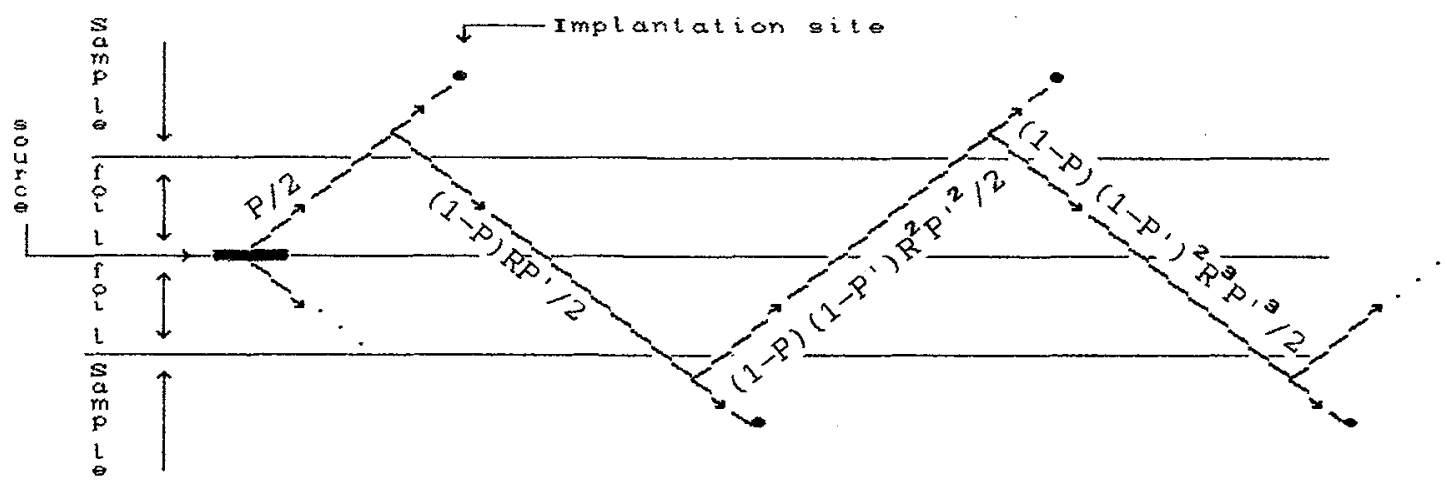

Figure 1. Multiple backscattering process: positron absorption outside the bulk matrix of a typical sample sandwich configuration.

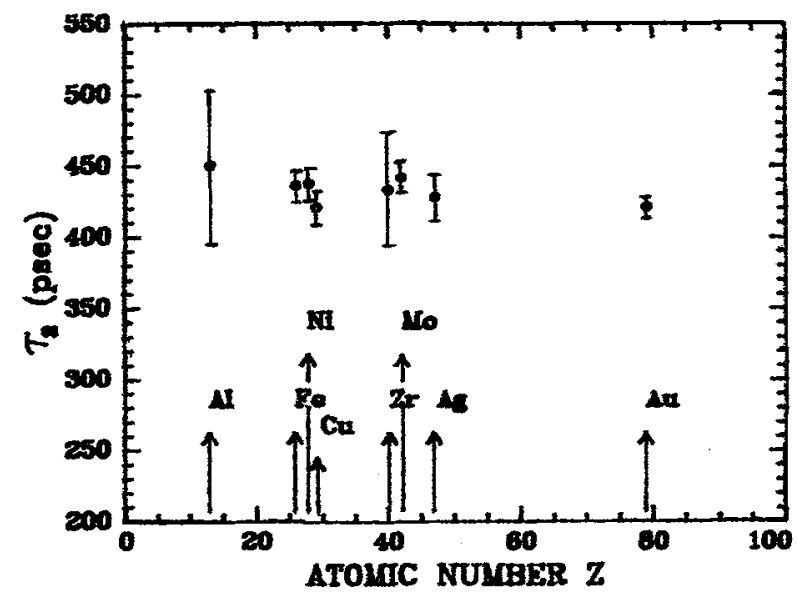

Figure 2. "Source-surface" Iifetimes 